\title{
A Ceramic Sensor for Prediction of Hydrogen Attack
}

\author{
Shigeru ANDO, Yasuharu HISAOKA'), Hideki HAMADA') and Kouji YAMAKAWA
}

Department of Metallurgical Engineering, College of Engineering, University of Osaka Prefecture, Mozuumemachi, Sakai, Osaka-fu, 591 Japan. 1) Graduate School, University of Osaka Prefecture.

(Received on July 2, 1990; accepted in the final form on September 14, 1990)

\begin{abstract}
A ceramic sensor for monitoring the hydrogen permeated through steels at high temperatures using an electrochemical method has been developed. A new proton conductive solid electrolyte $\left(5 \mathrm{~mol} \% \mathrm{Yb}_{2} \mathrm{O}_{3}-\mathrm{SrCeO}_{3}\right)$ was used as an electrolyte in this sensor. It was found possible to measure the diffusivity and the content of hydrogen permeated through a plain carbon steel at $773 \mathrm{~K}$ and $0.101 \mathrm{MPa}$ hydrogen gas by joining the sensor to the steel with a platinum past. However, the detectability of hydrogen was poor, because joining of ceramics/steel exerted a large influence on it. Joining of the ceramics to the platinum-plated steel with amorphous copper filler metal led to the great improvement of the detectability of hydrogen. This sensor will be useful for predicting hydrogen attack of steels in operating chemical plants.
\end{abstract}

KEY WORDS: hydrogen attack; ceramic sensor; proton conductive solid electrolyte; diffusivity of hydrogen; hydrogen content.

\section{Introduction}

Steels exposed to hydrogen gas at high temperatures and high pressures often suffer from a marked reduction in their mechanical properties. This phenomenon, well known as hydrogen attack, ${ }^{1)}$ is caused primarily by nucleation, growth and coalescence of the methane bubbles along grain boundaries accompanied by concomitant internal decarburization.

There are many reports ${ }^{2-5)}$ on accidents and damage caused by hydrogen attack in petrorefining plants and ammonia production plants. However, there is no method in use for predicting or monitoring hydrogen attack. The only conventional method for avoiding hydrogen attack is to select materials adequate for the operating temperature and hydrogen pressure according to the Nelson chart, ${ }^{5}$ ) which has been compiled from empirical data.

Hydrogen attack is closely related to the content of hydrogen brought in a steel from high temperature and high pressure hydrogen environments. ${ }^{6)}$ Thus, if a detector or sensor is developed to measure the hydrogen content at high temperatures, it will be useful for predicting hydrogen attack of steels. One of the authors has developed a detector for measuring the hydrogen content in steels at elevated temperatures using an electrochemical method. ${ }^{7,8)}$ However, since a molten salt $(\mathrm{NaOH})$ was used as an electrolyte in the cell of this detector, argon gas had to be continuously flowed into the cell for preventing the cathodic reaction of air in the molten $\mathrm{NaOH}$. In addition, the steel was severely corroded. We, therefore, attempted to develop a new detector using a solid electrolyte, or a ceramic sensor, to solve these problems.

This study shows an electrochemical technique for measuring hydrogen permeated through a plain car- bon steel at $773 \mathrm{~K}$ with this ceramic sensor.

\section{Basic Concept to Measure Hydrogen Content}

The principle of the present electrochemical technique is shown in Fig. 1. Hydrogen is introduced from one side (the entry side) of steel, while the other side (the extraction side) is held at an anodic potential sufficient to ionize the hydrogen permeated through the steel. From the detected ionization current, the permeation rate of hydrogen can be evaluated. In this study, a new type proton conductive solid electrolyte ${ }^{9)}\left(5 \mathrm{~mol} \% \mathrm{Yb}_{2} \mathrm{O}_{3}-\mathrm{SrCeO}_{3}\right)$ was used. The following reaction occurs at the anode:

$$
H \rightarrow H^{+}+e^{-}
$$

while the following reaction takes place at the cathode:

$$
2 \mathrm{H}^{+}+1 / 2 \mathrm{O}_{2}+2 e^{-} \rightarrow \mathrm{H}_{2} \mathrm{O}
$$

The hydrogen content in a specimen changes with time according to Fick's second law. Theoretical permeation curves during build-up and decay processes are calculated by applying the law under appropriate initial and boundary conditions. ${ }^{10)}$ The diffusivity of hydrogen in a specimen is obtained by comparing the theoretical curves with the build-up and decay transient curves that are measured by changing the hydrogen pressure as shown in Fig. 2.

Fig. 3 shows the change of hydrogen distribution with time through the thickness of a flat specimen. In the steady state, the hydrogen content $C_{0}(\mathrm{ppm})^{11)}$ can be calculated from

$$
C_{0}=\frac{J_{\infty} \cdot L}{F \cdot D \cdot d}
$$

where, $J_{\infty}$ : the permeation current density in the 


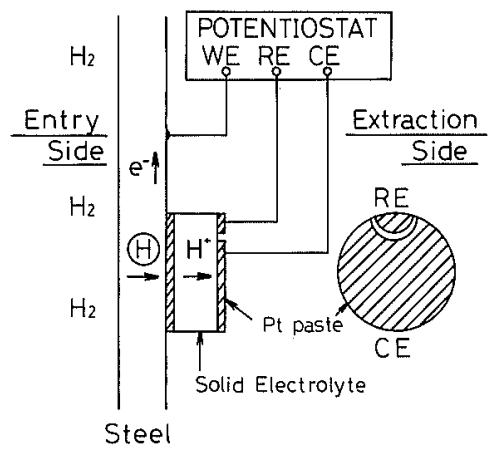

Fig. 1. Principle of the present electrochemical technique for measuring hydrogen permeated through steel using a solid electrolyte.

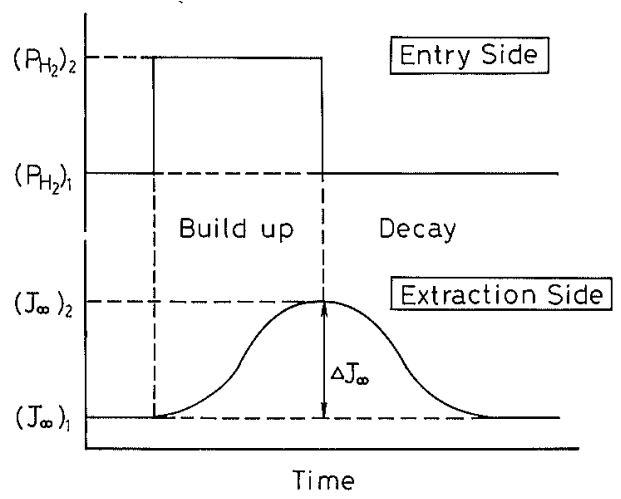

Fig. 2. Schematic representation of permeation transients in the build-up and decay processes.
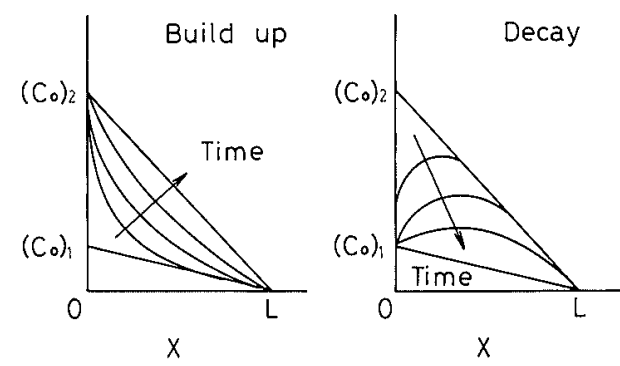

$X=0, X=L$ : the inner and outer surfaces, respectively

Fig. 3. Change in the concentration gradients of hydrogen in a flat specimen with time in the build-up and decay processes.

steady state $\left(\mathrm{A} \cdot \mathrm{m}^{-2}\right)$

$L:$ the specimen thickness $(\mathrm{m})$

$F:$ the Faraday constant

$D:$ the diffusivity of hydrogen in the specimen $\left(\mathrm{m}^{2} \cdot \mathrm{s}^{-1}\right)$

$d$ : the density of the specimen $(7.86 \mathrm{Mg}$. $\left.\mathrm{m}^{-3}\right)$.

\section{Experimental Procedures}

The apparatus for the present experiment is shown schematically in Fig. 4. The specimen had a hollow cylindrical shape and the thickness of its top was about three times thinner than the side. The chemical composition of the specimen is given in Table 1 . The inner and outer radii of the specimen were 12 and 18

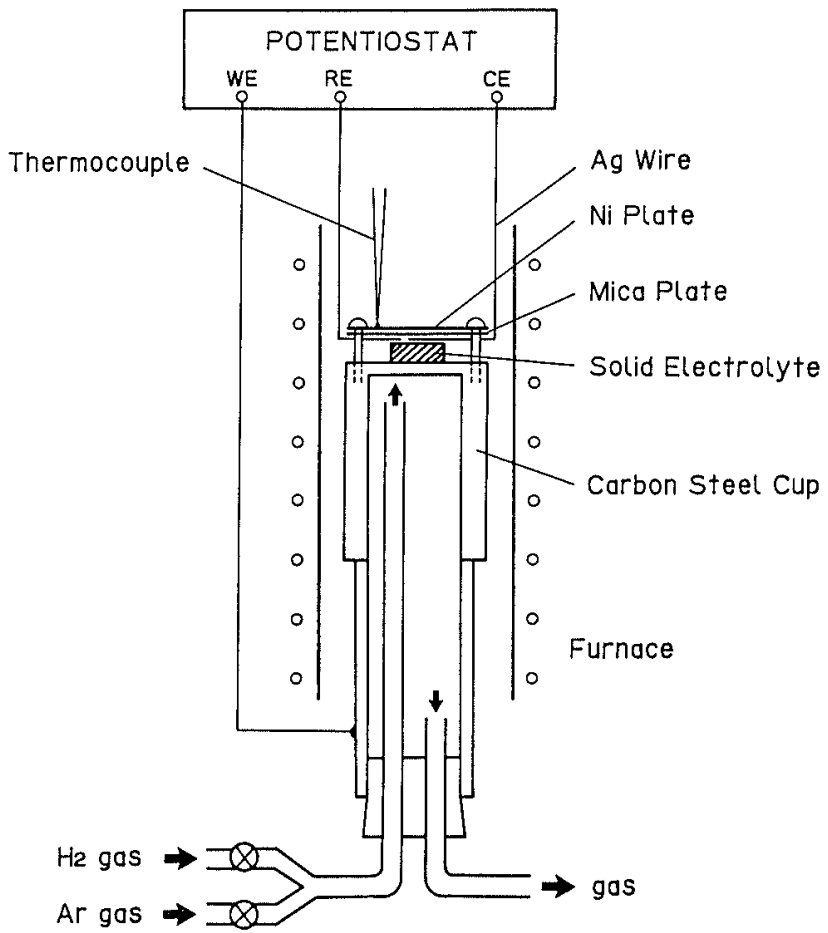

Fig. 4. Schematic diagram of the experimental apparatus.

Table 1. Chemical composition of the specimens. (mass\%)

\begin{tabular}{ccccccc}
\hline Specimen & $\mathrm{G}$ & $\mathrm{Si}$ & $\mathrm{Mn}$ & $\mathrm{P}$ & $\mathrm{S}$ & $\mathrm{Al}$ \\
\hline Carbon steel & 0.19 & 0.22 & 1.00 & 0.018 & 0.012 & 0.015 \\
\hline
\end{tabular}

$\mathrm{mm}$, respectively. The top of the specimen, into which a steel pipe was bonded by electron beam welding, separated the entry side and extraction side of the hydrogen.

On the entry side, argon gas was replaced to hydrogen gas (build-up) and vice versa (decay) at a flow rate of $1.7 \times 10^{-6} \mathrm{~m}^{3} \cdot \mathrm{s}^{-1}$ and at a gas pressure of 0.101 $\mathrm{MPa}$. On the extraction side, the hydrogen permeated through the steel was detected with the solid electrolyte mounted to the top of the specimen. The ceramics was $10 \mathrm{~mm}$ in diameter and $2 \mathrm{~mm}$ in thickness. It was used as a reference and a counter electrodes; they were separated by a coating porous platinum on the one side of the solid electrolyte as shown in Fig. 1. The platinum paste with which the ceramics was coated was dried for $1.8 \mathrm{ks}$ at $623 \mathrm{~K}$ and then sintered for $0.9 \mathrm{ks}$ at $1273 \mathrm{~K}$. After the treatment, joining of the solid electrolyte to the steel was made with a platinum paste at $773 \mathrm{~K}$.

Since it was difficult to get a good detectability of hydrogen by joining the solid electrolyte to the steels with the platinum past as will be described later, we tried to join the ceramics to the as-polished or metalplated steel using amorphous copper filler metal at $923 \mathrm{~K}$. The amorphous filler metal was about 0.03 $\mathrm{mm}$ in thickness and had the following chemical composition: $\mathrm{Ni}$ : $9.5, \mathrm{Sn}: 4.0, \mathrm{P}: 7.5$ mass $\%, \mathrm{Cu}$ : balance.

The hydrogen in the specimen was extracted at an anodic potential in the range of 0 to $160 \mathrm{mV}$ vs. 
$\mathrm{O}_{2}\left(\mathrm{SrCeO}_{3}\right) / \mathrm{H}_{2} \mathrm{O}$ (air). The temperature was maintained at a given temperature within $\pm 3 \mathrm{~K}$ by a controller with a thermocouple close to the furnace. The permeated transient current during the built-up and the decay processes was recorded as a function of time.

\section{Results and Discussion}

\subsection{Response of Solid Electrolyte to Hydrogen}

First, we investigated the response of the solid electrolyte to the change in the atmosphere from argon to hydrogen and vice versa. In this experiments, one side of the solid electrolyte was exposed directly to the atmosphere by drilling a hole of about $2 \mathrm{~mm}$ in diameter in the top of the steel specimen as shown in Fig. 4. A graphite sheet was put around the hole between the steel and the solid electrolyte and the three were fastened together with bolts to prevent a gas leak. The permeation current density was measured during the built-up and decay processes in the same way as described above.

An example of the measurements is illustrated in Fig. 5. Fig. 5 shows that the solid electrolyte used is very sensitive to the change in the atmosphere or hydrogen pressure.

\subsection{Relationship between Extraction Potential and Permea- tion Current Density}

A typical relationship between the extraction potential and the permeation current density at the steady state $\left(J_{\infty}\right)$ in a hydrogen pressure of $0.101 \mathrm{MPa}$ and in an argon pressure of $0.101 \mathrm{MPa}$ are shown in Fig. 6. The values of $J_{\infty}$ increased with increasing potential. Since the solid electrolyte used has only $p$-type conduction or hole conduction in an atmosphere free from hydrogen or water vapor, ${ }^{9)}$ this phenomenon is probably due to the increase in the residual anodic current by hole conduction. From the difference between the two steady state permeation currents $\left(\Delta J_{\infty}\right)$, or the net ionization current density, it can be seen that the most suitable potential range for detecting the permeated hydrogen is from 0 to $140 \mathrm{mV}$ vs. $\mathrm{O}_{2}\left(\mathrm{SrCeO}_{3}\right) / \mathrm{H}_{2} \mathrm{O}$ (air). Thus, we selected $80 \mathrm{mV}$ as an anodic potential sufficient to ionize the

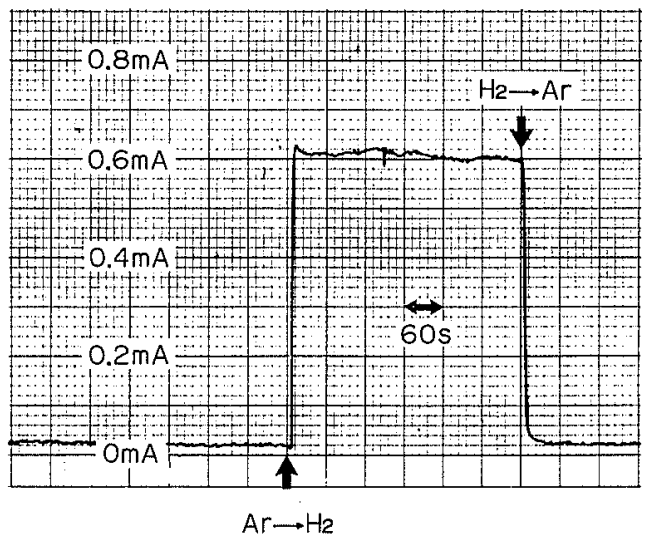

Fig. 5. Response of the solid electrolyte to the change in hydrogen pressure. hydrogen permeated through the steel.

\subsection{Permeation Curves and Diffusizity of Hydrogen}

A typical permeation curve for hydrogen at $80 \mathrm{mV}$ vs. $\mathrm{O}_{2}\left(\mathrm{SrCeO}_{3}\right) / \mathrm{H}_{2} \mathrm{O}$ (air) polarization is shown in Fig. 7, where the arrows show the changes in the atmosphere from argon to hydrogen for buildup and from hydrogen to argon for decay.

Fig. 8 shows a comparison between the theoretical curves (solid lines) and experimental data. The ordinate was normalized in units of $\Delta J_{t} / \Delta J_{\infty}$, and the plots were shifted on the abscissa to coincide with the theoretical curves at $\Delta J_{i} / \Delta J_{\infty}=0.5$. The experimental data agreed fairly well with the theoretical curves. This indicates that the following initial and boundary conditions at the entry and extraction surfaces were adequate:

for the build-up process,

$$
\begin{aligned}
& t=0,0 \leqq X \leqq L, C=0 \\
& t>0, X=0, C=C_{0} \\
& X=L, C=0
\end{aligned}
$$

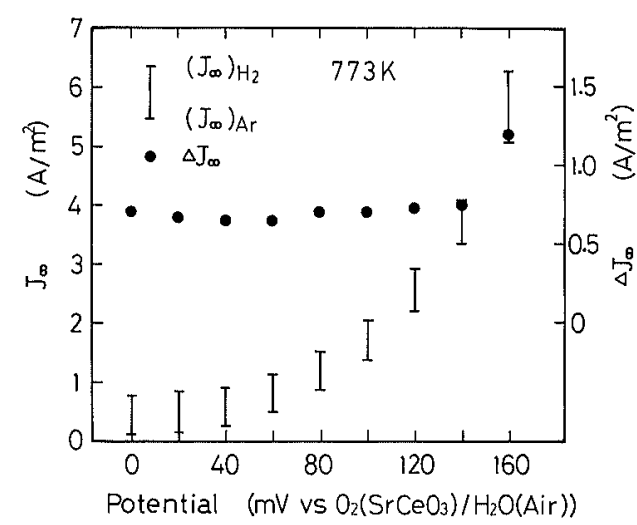

$J_{\infty}$ : the steady state permeation current density

$\Delta J_{\infty}$ : the difference between the two steady state permeation current densities, or the net ionization current density

Fig. 6. Relationship between permeation current density and extraction potential.

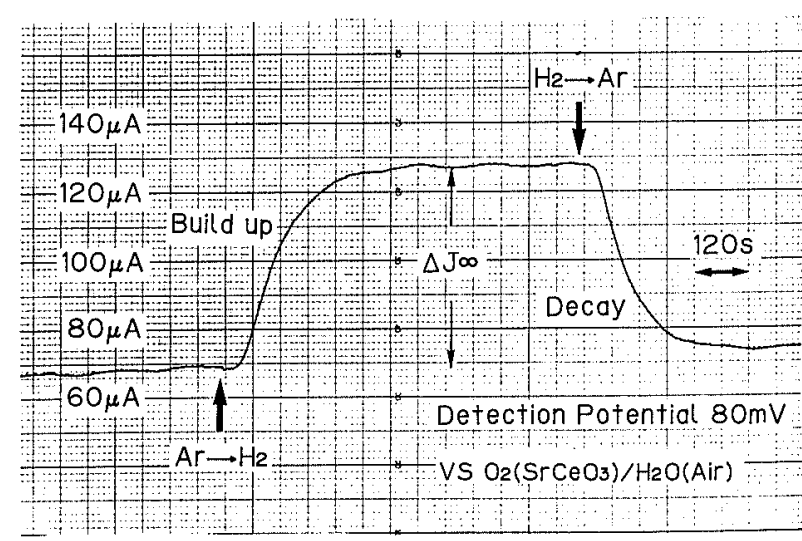

Arrows denote the points at which the atmosphere is replaced from argon to hydrogen (build-up) and vice versa (decay).

Fig. 7. Typical permeation transients in the build-up and decay processes at an extraction potential of $80 \mathrm{mV}$ vs. $\mathrm{O}_{2}\left(\mathrm{SrCeO}_{3}\right) / \mathrm{H}_{2} \mathrm{O}$ (air). 
Fig. 8.

Comparison between the theoretical permeation curves and experimental data in the build-up and decay transients.

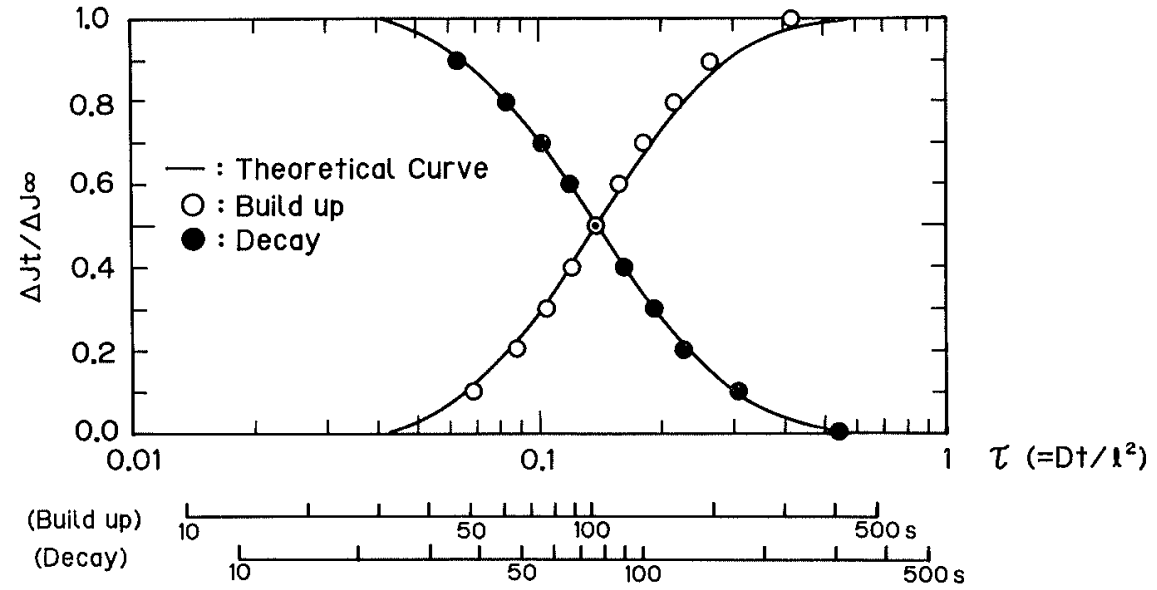

The diffusivity obtained from build-up and decay runs is plotted against the reciprocal of temperature in Fig. 9. The values obtained from the electrochemical method ${ }^{8)}$ and the conventional gaseous methods such as the gaseous permeation ${ }^{12-16)}$ and evolution techniques ${ }^{16-18)}$ are also shown in the figure. The diffusion coefficients of hydrogen for the carbon steel obtained from the build-up and decay runs were $8.71 \times 10^{-9}$ and $6.99 \times 10^{-9} \mathrm{~m}^{2} \cdot \mathrm{s}^{-1}$, respectively. These values were close to the ones measured by the electrochemical method using a molten sodium hydroxide electrolyte $^{8)}\left(1.27 \times 10^{-8}\right.$ and $\left.9.90 \times 10^{-9} \mathrm{~m}^{2} \cdot \mathrm{s}^{-1}\right)$ as shown in Fig. 9.

\subsection{Effect of Joining of Ceramics/Steel on Detectability of Hydrogen}

The detectability of hydrogen can be evaluated by comparing the hydrogen content obtained from the permeation current density with that calculated from Sievert's law:

$$
C_{0}(\mathrm{ppm})=a^{*} \sqrt{P_{\mathrm{HI}_{2}}} \exp (-\Delta H / R T)
$$

where, $a^{*}:$ a constant $\left(\mathrm{ppm} \cdot \mathrm{Pa}^{-1 / 2}\right)$

$P_{\mathrm{II}_{2}}$ : the hydrogen partial pressure $(\mathrm{Pa})$

$\Delta H$ : the enthalpy change associated with dissolution of hydrogen in steel $\left(\mathrm{kJ} \cdot \mathrm{mol}^{-1}\right)$

$R$ : the gas constant $\left(8.31 \times 10^{-3} \mathrm{~kJ} \cdot \mathrm{K}^{-2}\right.$. $\mathrm{mol}^{-1}$ )

$T$ : the reaction temperature $(\mathrm{K})$.

Fig. 10 shows the values of $C_{0}$ (hydrogen content) and $\Delta J_{\infty} \cdot L$ (hydrogen permeability) obtained from several build up and decay runs at $773 \mathrm{~K}$ and 0.101 $\mathrm{MPa}$ hydrogen gas. Broken lines in the figure represent the values of $C_{0}$ and $\Delta J_{\infty} \cdot L$ calculated from Eqs. (3) and (6). In this case, from the published data ${ }^{19-21)}$ for $a^{*}$ and $\Delta H$ and Fig. 9 for $D, 0.133$ $\mathrm{ppm} \cdot \mathrm{Pa}^{-1 / 2}, 27.2 \mathrm{~kJ} \cdot \mathrm{mol}^{-1}$ and $1.1 \times 10^{-8} \mathrm{~m}^{2} \cdot \mathrm{s}^{-1}$ were taken, respectively. The values obtained by joining the solid electrolyte to the as-polished steel using the platinum paste are much smaller than the calculated

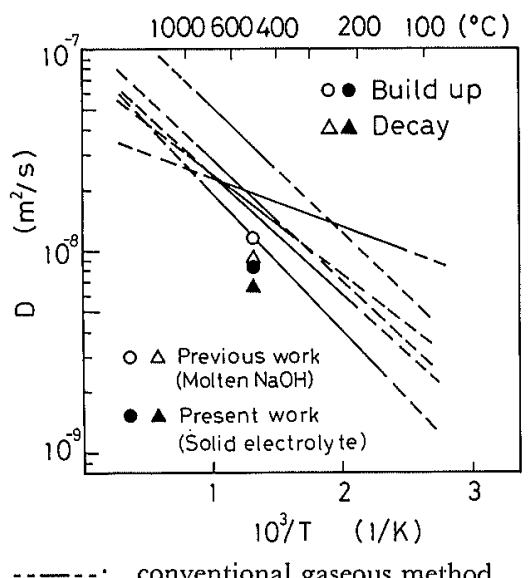

Fig. 9. Arrhenius plots of hydrogen diffusivities in carbon steel.

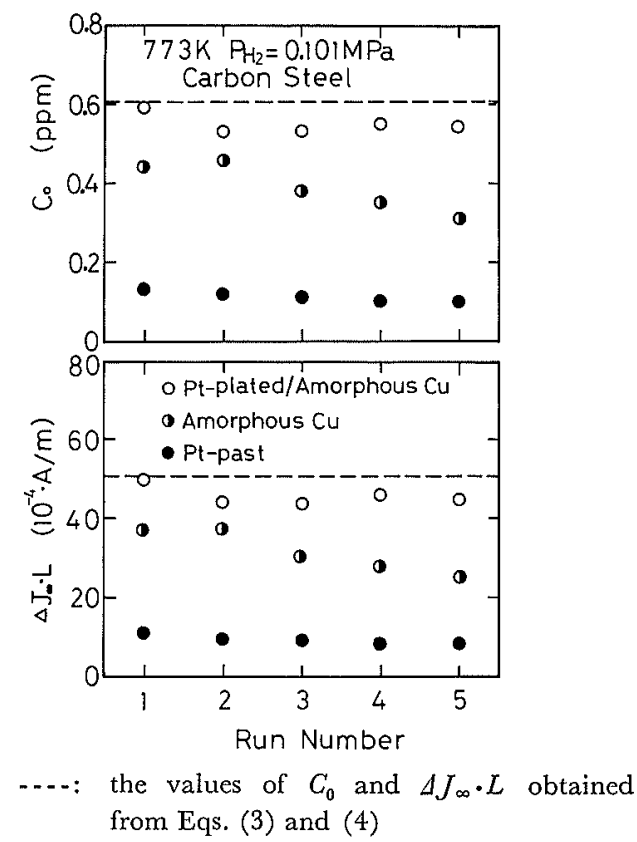

Fig. 10. Effect of joining of ceramics/steel on the hydrogen content $\left(C_{0}\right)$ and the hydrogen permeability $\left(\Delta J_{\infty}\right.$. L).

ones. This poor detectability of hydrogen is probably derived from the fact that most of atomic hydrogen permeated through the steels became hydrogen 
molecules and water vapor on the surfaces of the steels and/or porous platinum and escaped in the atmosphere. We, therefore, attempted to join the ceramics to the as-polished or metal-plated steel using a filler metal to prevent the escape of hydrogen. Fig. 10 also shows typical examples of these results. Of these, the values obtained by joining the ceramics to the platinum-plated steel with the amorphous filler metal are in fairly good agreement with that calculated ones, indicating that this joining of ceramics/ steel leads to the remarkable improvement of the detectability of hydrogen.

\section{Conclusions}

From these experiments, it was found possible to measure the diffusivity and the content of hydrogen permeated through the steel using the ceramic sensor. However, in order to put it into practical use, it will be required to monitor the hydrogen with high detectability for a long period. Thus, further improvement of joining of ceramics/steel is being made to meet the requirement.

\section{REFERENCES}

1) H. Tsubakino and K. Yamakawa: Tetsu-to-Hagané, 71 (1985), 1070.

2) K. Ishizuka and R. Chiba: Tetsu-to-Hagané, 56 (1970), 93.

3) K. Yamakawa: J. Soc. Mater. Sci., Jpn., 25 (1976), 1110

4) J. Watanabe: Tetsu-to-Hagané, 64 (1978), 1020.

5) API Publication 941, 3rd Ed., API, Washington, DG, (May
1983).

6) H. Tsubakino and K. Yamakawa: Corros. Eng. (Jpn.), 33 (1985), 159.

7) H. Tsubakino, K. Fukumoto and K. Yamakawa: Trans. Iron Steel Inst. Jpn., 28 (1988), 143.

8) H. Tsubakino and K. Yamakawa: Localized Corrosion, ed. by F. Hine, K. Komai and K. Yamakawa, Elsevier Appl. Sci., London, (1988), 101.

9) H. Iwahara, T. Esaka, H. Uchida and N. Maeda: Solid Siate Ionics, 3/4 (1981), 359.

10) S. Yoshizawa and K. Yamakawa: Corros. Eng. (Jpn.), 24 (1975), 365

11) H. Tsubakino, A. Ando, T. Masuda and K. Yamakawa: Trans. Iron Steel Inst. Jpn., 26 (1986), 775.

12) W. Geller and T-H. Sun: Arch. Eisenhïttenwes., 21 (1950), 423.

13) W. L. Bryan and B. F. Dodge: AlChE J., 9 (1963), 223

14) C. Sykes, H. H. Burton and C. G. Gegg: J. Iron Steel Inst., 156 (1947), 173.

15) H. Schunk and H. Taxhert: Arch. Eisenhüttenwes., 30 (1959), 661

16) W. Eichenauer, H. Kunzig and A. Pebler: Z. Metallkd. 49 (1958), 220.

17) F. F. Goe and J. Moreton: J. Iron Steel Inst., 204 (1966), 366.

18) T. M. Stross and F. C. Tompkins: J. Chem. Soc. London, (1956), 230

19) T. Sakai, K. Asami, M. Katsumata, H. Takada and O. Tanaka: Current Solutions to Hydrogen Problems in Steels, ed. by C. G. Interrante and C. M. Pressouyre, ASM, Metals Park, OH, (1982), 340.

20) M. H. Armbruster: J. Am. Chem. Soc., 65 (1943), 1043.

21) O. D. Gonzalez: Trans. Metall. Soc. AIME, 245 (1969), 607. 